\title{
30. GLASSY INCLUSIONS IN PLAGIOCLASE AND PYROXENE PHENOCRYSTS IN THE CHILLED MARGIN OF A PILLOW LAVA FROM HOLE 417D, DEEP SEA DRILLING PROJECT
}

\author{
Robert Clocchiatti, Laboratoire de Géochimie des Roches Sédimentaires, Bâtiment 504, \\ Faculté des Sciences, 91405 Orsay, France
}

\section{INTRODUCTION}

Glassy inclusions in magmatic minerals are small amounts of magma trapped in crystallographic defects of the host mineral during crystallization. Their study provides information about the minimum temperature of the liquid at the moment of entrapment, about water pressure, and about the chemical composition of the liquid. The evolution of these inclusions (by exchange between the host mineral and the enclosed liquid) is controlled by the cooling rate of the lava during its movement upward and during its emplacement. This paper presents the basalts of a study of such inclusions in a sample (417D-28-5, 15-19 cm) of Cretaceous basalt recovered from the oceanic basement during DSDP Leg 51.

\section{GLASSY INCLUSIONS IN PLAGIOCLASE PHENOCRYSTS}

The plagioclase phenocrysts studied (An8s) contain a large number of glassy inclusions located along crystal growth planes. The average dimension of these inclusions is less than $50 \mu \mathrm{m}$; that of the host mineral does not exceed $2000 \mu \mathrm{m}$. Three kinds of inclusions have been recognized, corresponding to three distinct zones in the sample (Figure 1):

Zone 1, corresponding to the outermost chilled margin of the pillow, is entirely composed of fresh glass. The average thickness of this zone is 4 to $5 \mathrm{~mm}$. Scarce plagioclase microphenocrysts are characterized by idiomorphic monophase inclusions ("negative crystals") composed entirely of glass.

Zone 2, located 4 to $8 \mathrm{~mm}$ from the pillow border, contains phenocrysts and some microlites of plagioclase (Analysis 22, Table 1) in a glassy matrix. Devitrification of the glass is marked by the formation of varioles around the microlites. Inclusions in the phenocrysts are composed of two phases: a dominant glass phase and a gaseous bubble or shrinkage vesicle. The outlines of the cavities are less sharp than in the previous zone, owing to the beginning of mineral crystallization on their walls. The beginning of recrystallization of the glass can be observed in some inclusions.

Zone 3, located 8 to $10 \mathrm{~mm}$ from the pillow border, is composed essentially of microlites, the number and size of which increase towards the core of the pillow. The presence of polyphase glassy inclusions characterizes the plagioclase phenocrysts of this zone. The glassy phase is replaced by numerous crystallites (pyroxenes and oxides) and a feldspathic rim appears on the walls of the cavities. The shrinkage vesicles are volumetrically more important than in Zone 2.

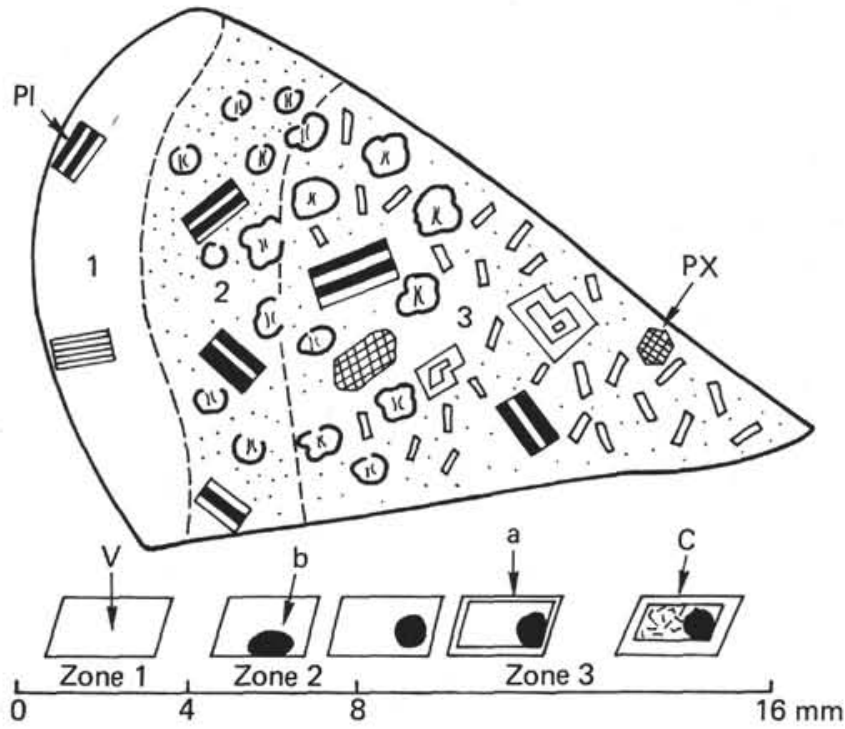

Figure 1. Schematic drawing of Sample 417D-28-5, 15-19 cm showing: (1) glassy chilled margin (Pl: plagioclase phenocrysts), (2) weakly crystallized zone, (3) strongly crystallized zone (Px: clinopyroxene phenocrysts). The different types of glassy inclusions observed in the plagioclases are shown below the sample. $V=$ glass, $b=$ gaseous bubble, $a=$ feldspar rim more sodic than the host mineral, $C=$ crystallites.

\section{Interpretation}

In Zone 1, the glassy inclusions have suffered drastic quenching (instantaneous or very fast cooling upon contact with sea water) and gaseous bubbles or shrinkage vesicles could not develop. A monophase filling of the inclusions thus corresponds to a high temperature of formation. A temperature of $1160^{\circ} \pm 20^{\circ} \mathrm{C}$ was measured by optical thermometry.

In Zone 2, the rate of cooling was lower than in Zone 1 and the viscosity was low enough to allow the formation of shrinkage vesicles at temperatures between $1100^{\circ}$ and $1050^{\circ} \mathrm{C}$. Neither the inclusions nor the cavities have undergone subsequent change.

In Zone 3, the rate of cooling was even slower than in Zone 2. This permitted the formation of shrinkage vesicles. The crystallization of mafic minerals in the residual liquid and the crystallization in cavities of the feldspars are more sodic than the host crystals (Figure 2).

At the moment of emplacement of the lava, the difference in temperature between the margin and the center of the 
TABLE 1

Microprobe Analysis of Host Plagioclase Phenocrysts (wt. \% composition)

\begin{tabular}{lrrrrrrrrrrrr}
\hline & \multicolumn{1}{c}{3} & \multicolumn{1}{c}{7} & \multicolumn{1}{c}{31} & \multicolumn{1}{c}{32} & \multicolumn{1}{c}{33} & \multicolumn{1}{c}{34} & \multicolumn{1}{c}{35} & \multicolumn{1}{c}{36} & \multicolumn{1}{c}{37} & \multicolumn{1}{c}{53} & 22 & mean \\
\hline $\mathrm{SiO}_{2}$ & 46.72 & 47.11 & 47.01 & 47.67 & 46.87 & 47.67 & 46.31 & 45.42 & 46.07 & 47.74 & 48.46 & 46.72 \\
$\mathrm{TiO}_{2}$ & - & 0.06 & 0.01 & 0.07 & - & 0.03 & - & 0.06 & - & 0.09 & - & 0.07 \\
$\mathrm{Al}_{2} \mathrm{O}_{3}$ & 33.18 & 32.42 & 32.77 & 32.88 & 33.21 & 32.68 & 32.87 & 33.06 & 33.55 & 32.01 & 31.70 & 33.00 \\
$\mathrm{FeO}$ & 0.29 & 0.26 & 0.58 & 0.63 & 0.51 & 0.57 & 0.40 & 0.31 & 0.36 & 0.52 & 0.71 & 0.48 \\
$\mathrm{CaO}$ & 17.70 & 17.10 & 17.39 & 17.10 & 17.88 & 17.86 & 17.76 & 17.98 & 17.93 & 16.53 & 16.37 & 17.70 \\
$\mathrm{Na}_{2} \mathrm{O}$ & 1.47 & 1.71 & 1.86 & 1.71 & 1.65 & 1.62 & 1.32 & 1.23 & 1.29 & 1.99 & 2.48 & 1.53 \\
$\mathrm{~K}_{2} \mathrm{O}$ & 0.04 & - & - & - & - & - & 0.05 & 0.04 & - & 0.03 & - & 0.04 \\
Total & 99.58 & 98.67 & 101.17 & 100.66 & 100.47 & 100.42 & 98.79 & 98.10 & 99.36 & 98.98 & 99.82 & 99.54 \\
\hline
\end{tabular}

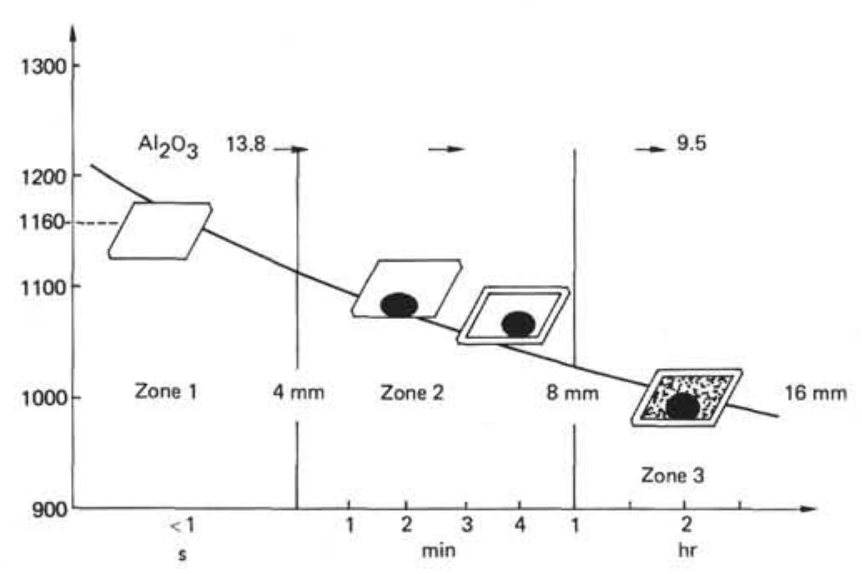

Figure 2. Quenching temperature of inclusions and estimated time of cooling according to experimental data measured by optical thermometry (Clocchiatti, 1978).

sample studied was approximately $200^{\circ} \mathrm{C}$. Cooling was nearly instantaneous in the outermost zone; lasting a few minutes in Zone 2, and a few hours in Zone 3. The phenomena observed in this sample have been confirmed experimentally (Clocchiatti, 1978).

\section{CHEMICAL COMPOSITION OF THE GLASSY INCLUSIONS}

Microprobe analyses (CAMEBAX, B.R.G.M.-C.N.R.S., Orleans La Source) have been made: (a) on the glassy inclusions in plagioclase (Analyses 4 to 13 , Table 2) and pyroxene (Analyses 54 to 61 , Table 3); (b) in the glassy mesostasis (Analyses 19 to 47, Table 4); (c) in the host plagioclase
(Analyses 3 to 22, Table 1) and pyroxene (Analyses 55 to 63, Table 5); and (d) immiscible on an pentlandite globule observed in an inclusion in plagioclase (Analysis X, Table 4).

\section{Glassy Inclusions in Plagioclase}

The chemical composition of the glassy inclusions in the plagioclase phenocrysts varies between two extremes: nonevolved inclusions (Analyses 4 to 30, Table 2) which are similar in composition to that of the initial liquid and evolved inclusions which have been affected by growth of the host mineral at the expense of the trapped liquid during relatively slow cooling (Analyses 16 to 13 , Table 2 ). In the latter case, a decrease in abundance of the elements entering into the host mineral can be observed. For example, the $\mathrm{Al}_{2} \mathrm{O}_{3}$ content ranges from 13.3 per cent in the non-evolved liquid to 9.5 per cent in the evolved ones, while $\mathrm{Na}_{2} \mathrm{O}$ decreases from 2.4 per cent to 0.5 per cent or less. The $\mathrm{MgO} / \mathrm{FeO}$ ratio $(0.82$ to 0.92$)$ varies very little in the inclusions studied. A slight enrichment in iron content in the trapped liquids has been noticed, however. This enrichment could be due to the crystallization of small quantities of olivine. Moreover, the variations from non-evolved to evolved inclusions correspond precisely to the location of the host minerals in the sample. The non-evolved liquids are located in crystals of the peripheral zone (Zone 1) and the most evolved ones are found in the innermost zone (Zone 3). This evolution depends directly on the cooling rate, which is slowest in Zone 3 . The segment ab in the diagram $\mathrm{CaO}, \mathrm{Al}_{2} \mathrm{O}_{3}, \mathrm{MgO}$ (Figure 3) represents this chemical evolution between the two types of inclusions. A weak zoning in the plagioclases has been noted in the vicinity of some inclusions (Figure 4).

TABLE 2

Microprobe Analysis of Glassy Inclusions in Plagioclase (wt. \% composition) ${ }^{\text {a }}$

\begin{tabular}{|c|c|c|c|c|c|c|c|c|c|c|c|c|c|c|c|c|c|c|c|c|c|c|}
\hline & 4 & 25 & 26 & 27 & 28 & 29 & 30 & mean & 8 & 9 & 10 & 11 & 42 & 43 & 44 & 45 & 46 & 16 & 17 & 18 & 12 & 13 \\
\hline $\mathrm{SiO}_{2}$ & 50.82 & 50.86 & 50.12 & 49.92 & 50.49 & 50.55 & 50.22 & 50.36 & 50.17 & 50.39 & 49.52 & 49.90 & 51.03 & 50.82 & 49.59 & 50.65 & 50.74 & 50.24 & 50.79 & 50.29 & 50.93 & 51.46 \\
\hline $\mathrm{TiO}_{2}$ & 0.91 & 0.35 & 0.43 & 0.35 & 0.36 & 0.34 & 0.27 & 0.35 & 0.36 & 0.33 & 0.33 & 0.34 & 0.29 & 0.31 & 0.40 & 0.31 & 0.22 & 0.49 & 0.57 & 0.52 & 0.30 & 0.50 \\
\hline $\mathrm{Al}_{2} \mathrm{O}_{3}$ & 13.83 & 13.43 & 14.33 & 14.15 & 14.03 & 14.14 & 12.61 & 13.78 & 13.95 & 14.77 & 13.93 & 11.72 & 13.91 & 13.77 & 13.68 & 13.67 & 13.53 & 9.65 & 9.83 & 9.40 & 9.37 & 9.72 \\
\hline $\mathrm{Fe}_{2} \mathrm{O}_{3}$ & - & - & - & - & - & - & - & - & - & - & - & - & - & - & - & - & - & - & - & - & - & - \\
\hline $\mathrm{FeO}$ & 9.15 & 10.57 & 9.83 & 9.92 & 9.91 & 10.10 & 9.61 & 9.99 & 11.02 & 10.20 & 11.48 & 11.89 & 9.80 & 10.42 & 9.89 & 9.74 & 10.43 & 14.57 & 13.41 & 13.93 & 14.26 & 13.60 \\
\hline $\mathrm{MnO}$ & 0.15 & 0.25 & 0.16 & 0.30 & 0.07 & 0.06 & 0.11 & 0.16 & 0.17 & 0.23 & 0.28 & - & 0.01 & 0.16 & 0.12 & 0.13 & 0.09 & 0.32 & 0.27 & 0.09 & 0.28 & 0.44 \\
\hline $\mathrm{MgO}$ & 8.46 & 9.43 & 8.75 & 8.87 & 8.65 & 8.94 & 9.68 & 9.05 & 9.78 & 9.07 & 9.02 & 10.62 & 9.02 & 9.00 & 9.22 & 9.08 & 9.31 & 11.90 & 11.41 & 11.98 & 12.26 & 11.56 \\
\hline $\mathrm{CaO}$ & 11.65 & 11.78 & 11.95 & 12.05 & 12.25 & 12.14 & 11.87 & 12.01 & 11.27 & 11.30 & 11.28 & 11.70 & 11.73 & 11.53 & 11.74 & 11.57 & 11.56 & 10.91 & 11.33 & 11.46 & 10.74 & 10.61 \\
\hline $\mathrm{Na}_{2} \mathrm{O}$ & 2.41 & 2.09 & 2.32 & 2.40 & 2.20 & 2.40 & 2.24 & 2.28 & 2.04 & 1.83 & 2.28 & 2.26 & 2.52 & 2.53 & 2.33 & 2.41 & 2.60 & 0.20 & 0.19 & 0.17 & 0.76 & 0.50 \\
\hline $\mathrm{K}_{2} \mathrm{O}$ & 0.28 & 0.06 & 0.06 & 0.02 & 0.10 & 0.04 & 0.02 & 0.05 & 0.45 & 0.32 & 0.12 & 0.40 & 0.09 & - & 0.09 & 0.02 & 0.06 & 0.08 & 0.07 & 0.21 & 0.05 & 0.11 \\
\hline $\mathrm{Cr}_{2} \mathrm{O}_{3}$ & - & 0.07 & - & 0.01 & - & 0.14 & - & 0.04 & 0.24 & 0.33 & - & 0.44 & - & 0.20 & - & 0.11 & 0.11 & 0.07 & 0.02 & - & 0.12 & 0.06 \\
\hline Total & 97.81 & 98.87 & 97.94 & 97.98 & 98.07 & 98.85 & 96.64 & 98.07 & 99.44 & 99.13 & 97.92 & 99.20 & 98.49 & 98.82 & 97.22 & 97.79 & 98.72 & 98.53 & 97.89 & 97.05 & 99.07 & 98.56 \\
\hline
\end{tabular}

$a_{4}$ to 30: non-evolved inclusions in Zone 1; 8 to 46 : intermediate composition of inclusions in Zone 2; 16 to 13: evolved inclusions in Zone 3. 
TABLE 3

Microprobe Analysis of Glassy Inclusions in Clinopyroxene (wt. \% composition)

\begin{tabular}{|c|c|c|c|c|c|c|c|}
\hline & 54 & 56 & 57 & 58 & 59 & 60 & 61 \\
\hline $\mathrm{SiO}_{2}$ & 50.16 & 50.22 & 51.21 & 50.72 & 50.63 & 50.36 & 49.26 \\
\hline $\mathrm{TiO}_{2}$ & 1.41 & 1.39 & 1.29 & 1.32 & 1.37 & 1.35 & 1.34 \\
\hline $\mathrm{Al}_{2} \mathrm{O}_{3}$ & 13.98 & 13.46 & 13.79 & 13.72 & 13.43 & 13.84 & 13.53 \\
\hline $\mathrm{Fe}_{2} \mathrm{O}_{3}$ & - & - & - & - & - & - & - \\
\hline $\mathrm{FeO}$ & 10.81 & 10.82 & 11.16 & 11.10 & 10.53 & 10.45 & 10.63 \\
\hline $\mathrm{MnO}$ & - & - & - & - & - & - & - \\
\hline $\mathrm{MgO}$ & 7.74 & 8.12 & 7.90 & 7.62 & 8.10 & 7.83 & 7.68 \\
\hline $\mathrm{CaO}$ & 11.90 & 11.62 & 11.74 & 12.01 & 11.59 & 11.92 & 12.13 \\
\hline $\mathrm{Na}_{2} \mathrm{O}$ & 2.45 & 2.59 & 2.59 & 2.42 & 2,47 & 2.52 & 2.32 \\
\hline $\mathrm{K}_{2} \mathrm{O}$ & 0.02 & 0.07 & 0.04 & 0.11 & 0.06 & 0.01 & 0.01 \\
\hline $\mathrm{Cr}_{2} \mathrm{O}_{3}$ & - & 0.19 & 0.02 & - & 0.04 & - & 0.06 \\
\hline $\mathrm{NiO}$ & 0.17 & 0.35 & - & 0.09 & - & - & - \\
\hline Total & 98.91 & 98.85 & 99.94 & 99.31 & 98.37 & 98.41 & 97.10 \\
\hline
\end{tabular}

TABLE 4

Microprobe Analysis of the Glassy Mesostasis (wt. \% composition) ${ }^{\mathrm{a}}$

\begin{tabular}{lrrrrrrc}
\hline & \multicolumn{1}{c}{47} & \multicolumn{1}{c}{49} & \multicolumn{1}{c}{50} & mean & \multicolumn{1}{c}{20} & 19 & $\mathrm{X}$ \\
\hline $\mathrm{SiO}_{2}$ & 50.39 & 50.20 & 50.61 & 50.40 & 50.28 & 50.43 & 0.02 \\
$\mathrm{TiO}_{2}$ & 1.58 & 1.47 & 1.25 & 1.43 & 1.45 & 1.48 & 0.12 \\
$\mathrm{Al}_{2} \mathrm{O}_{3}$ & 14.17 & 14.43 & 14.89 & 14.50 & 14.00 & 14.57 & - \\
$\mathrm{Fe}_{2} \mathrm{O}_{3}$ & - & - & - & - & - & - & - \\
$\mathrm{FeO}$ & 11.09 & 10.60 & 10.28 & 10.66 & 10.03 & 10.87 & 66.59 \\
$\mathrm{MnO}$ & 0.28 & 0.03 & 0.18 & 0.16 & 0.25 & 0.18 & 0.06 \\
$\mathrm{MgO}$ & 7.65 & 7.45 & 7.77 & 7.62 & 7.74 & 7.71 & - \\
$\mathrm{CaO}$ & 11.84 & 11.94 & 12.07 & 11.95 & 11.83 & 11.91 & - \\
$\mathrm{Na}_{2} \mathrm{O}$ & 2.69 & 2.39 & 2.62 & 2.57 & 2.59 & 0.70 & - \\
$\mathrm{K}_{2} \mathrm{O}$ & 0.06 & 0.12 & 0.02 & 0.07 & 0.15 & 0.18 & - \\
$\mathrm{Cr}_{2} \mathrm{O}_{3}$ & 0.04 & - & 0.01 & 0.3 & 0.17 & 0.22 & \\
$\mathrm{NiO}$ & - & 0.35 & - & - & 0.26 & - & 30.75 \\
$\mathrm{Total}$ & 99.79 & 98.98 & 99.71 & 99.66 & 98.74 & 98.25 & 97.52 \\
\hline
\end{tabular}

${ }^{\mathrm{a}} \mathrm{X}$ : Analysis of a sulfide globule (pentlandite?) in a glassy inclusion in plagioclase.

TABLE 5

Microprobe Analysis of Host Clinopyroxene Phenocrysts (wt. \% composition)

\begin{tabular}{|c|c|c|c|c|}
\hline & 55 & 62 & 63 & Mean \\
\hline $\mathrm{SiO}_{2}$ & 51.66 & 52.10 & 52.92 & 52.23 \\
\hline $\mathrm{TiO}_{2}$ & 0.46 & 0.48 & 0.16 & 0.37 \\
\hline $\mathrm{Al}_{2} \mathrm{O}_{3}$ & 2.93 & 3.51 & 3.50 & 3.31 \\
\hline $\mathrm{Fe}_{2} \mathrm{O}_{3}$ & - & - & - & - \\
\hline $\mathrm{FeO}$ & 5.40 & 4.73 & 5.22 & 5.12 \\
\hline $\mathrm{MnO}$ & 0.10 & - & 0.19 & 0.10 \\
\hline $\mathrm{MgO}$ & 17.65 & 17.39 & 17.18 & 17.41 \\
\hline $\mathrm{CaO}$ & 20.03 & 20.27 & 20.59 & 20.30 \\
\hline $\mathrm{Na}_{2} \mathrm{O}$ & 0.24 & 0.28 & 0.20 & 0.24 \\
\hline $\mathrm{K}_{2} \mathrm{O}$ & 0.02 & - & - & - \\
\hline $\mathrm{Cr}_{2} \mathrm{O}_{3}$ & 0.67 & 0.89 & 0.99 & 0.87 \\
\hline $\mathrm{NiO}$ & 0.66 & 0.25 & 0.90 & 0.60 \\
\hline Total & 99.82 & 99.91 & 101.85 & 100.53 \\
\hline
\end{tabular}

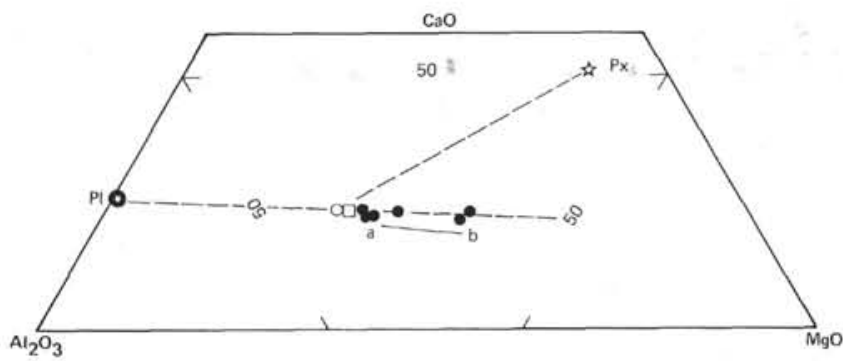

Figure 3. $\mathrm{CaO}, \mathrm{Al}_{2} \mathrm{O}_{3}, \mathrm{MgO}$ diagram after Watson (1976). o average mesostasis composition (four analyses); $\square$ average composition of glassy inclusions in pyroxene (Seven inclusions analyzed); compositions of 16 glassy inclusions in plagioclase phenocrysts from Zones 1 (a) and $3(\mathrm{~b}) . P x=$ pyroxene, $P l=$ plagioclase. After the growth of plagioclase on the cavity walls, the initial liquid $(a)$ is changed to $(b)$.
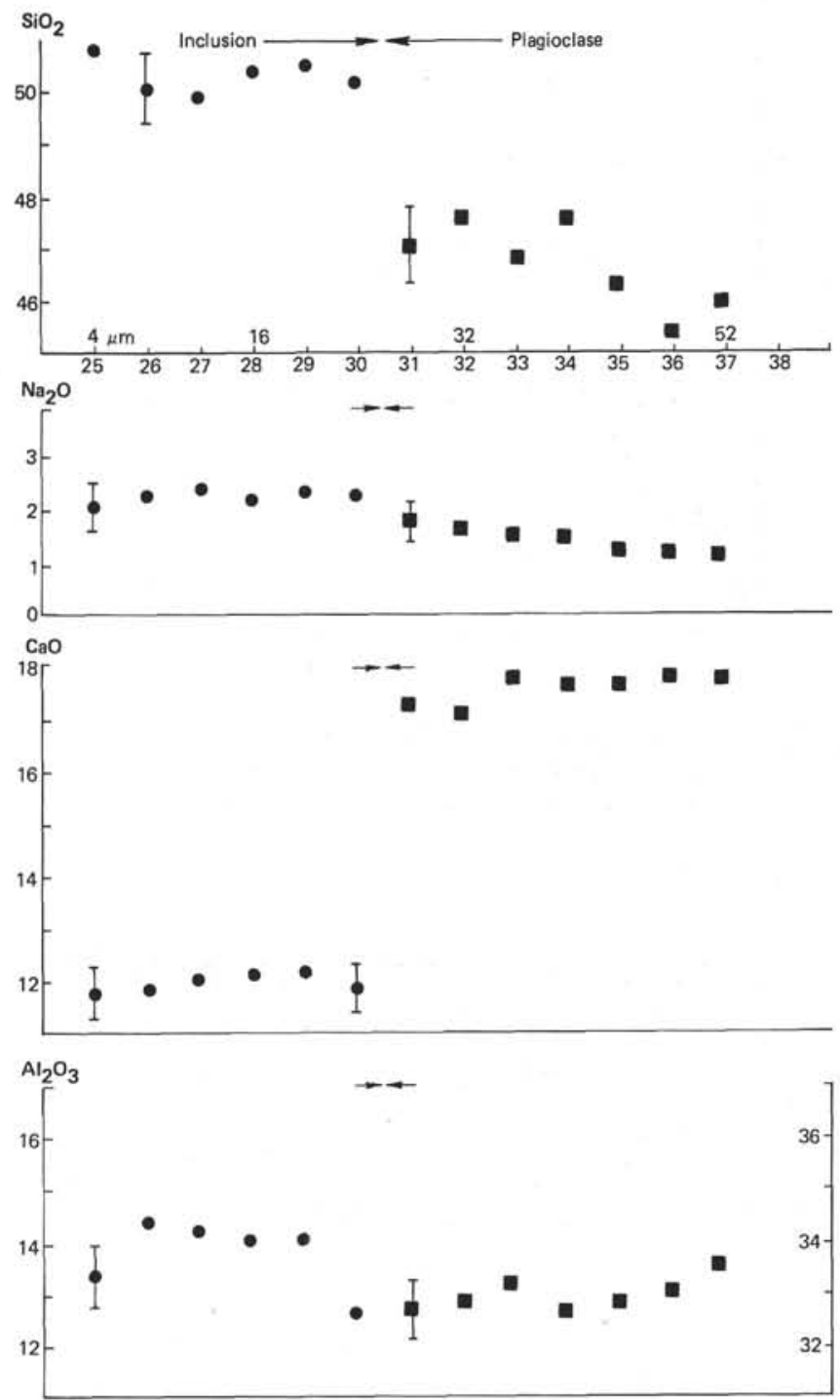

Figure 4. Variation in chemical composition across a plagioclase/glassy inclusion boundary in Zone 2 (Figure SD). Analysis numbers along horizontal axis. 

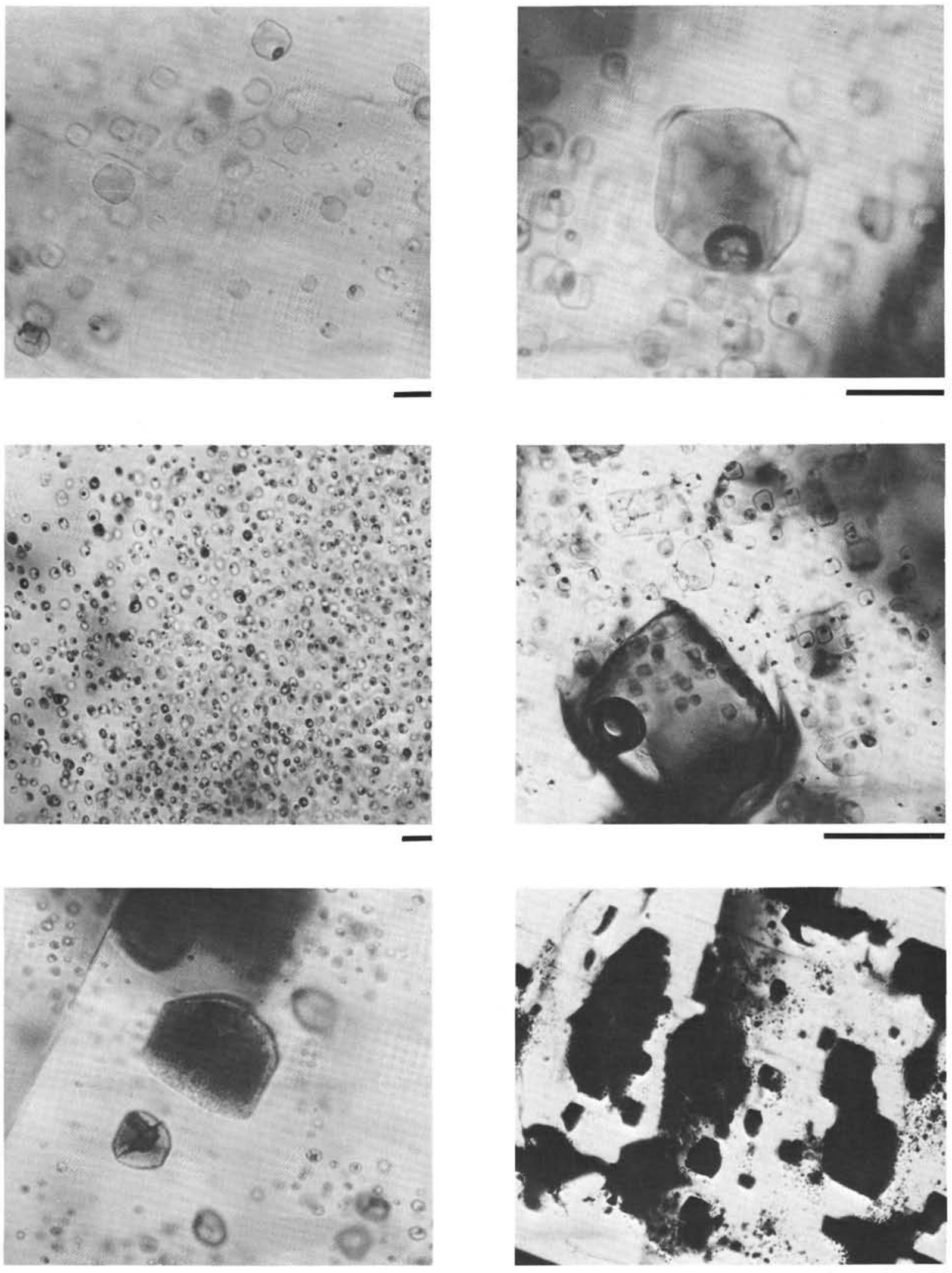

Figure 5. Photomicrographs showing different types of inclusions. A = monophase inclusions with glassy fillings $(Z 0$ ne 1). $B=$ two-phase inclusion with glass and a shrinkage vesicle; the inclusion exhibits an epitaxial feldspar rim on the wall of the cavity. $C$ and $D=$ crystal growth front in Zone 2 underlain by plane of inclusions. $E=b e g i n n i n g$ of crystallization in an inclusion in Zone 3. F = completely recrystallized inclusions in Zone 3. Scale represents $41 \mu \mathrm{m}$. 


\section{Glassy Inclusions in Pyroxene}

Seven glassy inclusions have been analyzed in the pyroxenes. The large size of the cavities (100 to $200 \mu \mathrm{m}$ ) and their irregular outlines suggest that the pyroxenes crystallized very quickly. Compared to the inclusions in the plagioclase phenocrysts, those in the pyroxenes do not show any evolution after the isolation of the cavities. The chemical compositions of the glass inclusions (Analyses 54 to 61, Table 3) are very close to the composition of the mesostasis (Analyses 47 to 50, Table 4). An increase in the $\mathrm{TiO}_{2}$ content can be noticed, both in the inclusions and the mesostasis - from 0.40 to 0.80 per cent when the plagioclase crystallizes and to 1.40 per cent when the pyroxenes crystallize. The $\mathrm{MgO}$ content of the liquid decreases by 1 to 1.5 per cent after crystallization of the $\mathrm{Mg}$-rich pyroxene $(\mathrm{MgO} / \mathrm{FeO}=0.86$ to 0.92 per cent at the moment of plagioclase crystallization and 0.69 to 0.74 per cent at the moment of pyroxene crystallization).

\section{CONCLUSIONS}

The initial results of studies by combined optical thermometry and microprobe analysis of glassy inclusions trapped in plagioclase and pyroxene phenocrysts in Sample 417D-28-5, 15-19 cm lead to the following conclusions:
1) During emplacement, the first few centimeters of lava in contact with sea water undergo differential rates of cooling;

2) This phenomena is responsible for the differences in character and chemical composition observed between inclusions in plagioclase from the outermost to the innermost zones of the pillow margin;

3) The minimum temperature of crystallization measured by homogenization of the fillings of the cavities with a heating device is $1160^{\circ} \pm 20^{\circ} \mathrm{C}$;

4) $\mathrm{The}_{\mathrm{pH}} \mathrm{O}$ calculated after plotting this temperature in P, T, C experimental diagrams (Mathez, 1971) is approximately $0.6 \mathrm{Kbar}$

5) The chemical composition of the magma during crystallization is characteristic of tholeiitic basalts;

6) The pyroxenes crystallize after plagioclase in the liquid (the composition of which is very close to that of the mesostasis), causing an enrichment in $\mathrm{TiO}_{2}$, a slight increase in $\mathrm{FeO}$ content, and a decrease in $\mathrm{MgO}$.

\section{REFERENCES}

Clocchiatti, R., Havette, A., Weiss, J., and Wilhelms, S., 1978. Mineral. Cristallogr. Bull., v. 101, p. 66-77.

Mathez, E.A., 1971. Contrib. Mineral., v. 41, p. 61-72.

Watson, E.B., 1976. Volcanol. Geochem. Res., v. 1, p. 73-84. 